\title{
A framework for managing geotechnical risk across multiple operations
}

\author{
by P.J.H. de Graaf* and S.D.N. Wessels ${ }^{\dagger}$
}

\section{Synopsis}

Rio Tinto's Western Australian expansion, combined with mining within structurally complex geology and increasingly below the water table, presents challenges in effective slope management to ensure safe and economic mining.

The Geotechnical Management System (GMS) was developed by Rio Tinto Iron Ore (RTIO) to manage geotechnical risks identified during the design process and implementation, and to ensure feedback based on the 'as-found' conditions. The GMS utilizes a risk-based approach to geotechnical risk management and is centred on the geotechnical risk and hazard assessment management system (GRAHAMS). GRAHAMS is used to assess pre- and post-control risk for future potential risks (planned slopes), current risks (as-built slopes), and actual geotechnical hazards (realized risks) identified in the pit. This serves as a core operational risk management tool in identifying and prioritizing key risk sectors and management of critical controls. The system's database reporting functionality supports effective communication of operational risks to operational personnel, as well as reporting the risk profile across operations to management.

A rigorous engagement process between design engineers and sitebased engineers is implemented to ensure that key design assumptions, limitations, risks, and opportunities are understood by the site teams. This information, together with mine plan schedule details, is used to assess the design risk and develop appropriate controls. These controls typically include slope performance monitoring and slope reconciliation. The design feedback loop is closed through sharing of key slope performance and reconciliation data with the design teams.

The GMS has been successfully implemented in RTIO pits and is fundamental to successful geotechnical slope management. Improved characterization of design assumptions has allowed for re-assessment of the pit design and improved hazard management in high-risk pits. The GMS, GRAHAMS, and other processes reduce the incidence of unexpected slope instability. Improved understanding of rock mass conditions has allowed for economic optimization through redesign of slopes, allowing for an improved understanding of risk and fewer unexpected conditions (surprises), hence an increased realized value.

Keywords

open pit mining, slope management, geotechnical risk, hazard assessment.
2016. Since 2007 RTIO has commissioned five new mines.

\section{Background}

The geology of the Pilbara is structurally complex with multiple deformation events resulting in significant folding and faulting. The complex structure (often resulting in bedding dipping adversely into the pit void), major expansions below the water table, and detrital sequences present a challenging geotechnical environment to design and implement mine slopes while maximizing ore recovery. Orebodies typically comprise multiple ore pods, resulting in multi-pit mines, where a number of pits can be active at one time (depending on product quality requirements).

Most mines have site-based geotechnical engineers with support from a Perth geotechnical team. Before 2010, geotechnical risk management at RTIO Pilbara Operations was site-based. The skill and experience of geotechnical teams across the Pilbara varied and most geotechnical engineers had less than five years of experience. The situation was further exacerbated by the Australian mining boom, resulting in a scarcity of qualified and experienced geotechnical engineers, limited across-site support, and lack of standardization of systems and tools. Slope management systems were variable, with the level of rigour depending upon the experience of the site-based engineers. This resulted in inconsistencies in perceived levels of risk, and consequently it was difficult for a holistic business risk profile (and prioritization) to be communicated to management.

* De Beers Group of Companies, previously Rio Tinto Iron Ore.

$\uparrow$ Rio Tinto Iron Ore.

(C) The Southern African Institute of Mining and Metallurgy, 2016. ISSN 2225-6253. This paper was first presented at the, International Symposium on Slope Stability in Open Pit Mining and Civil Engineering 2015, 12-14 October 2015, Cape Town Convention Centre, Cape Town. 


\section{A framework for managing geotechnical risk across multiple operations}

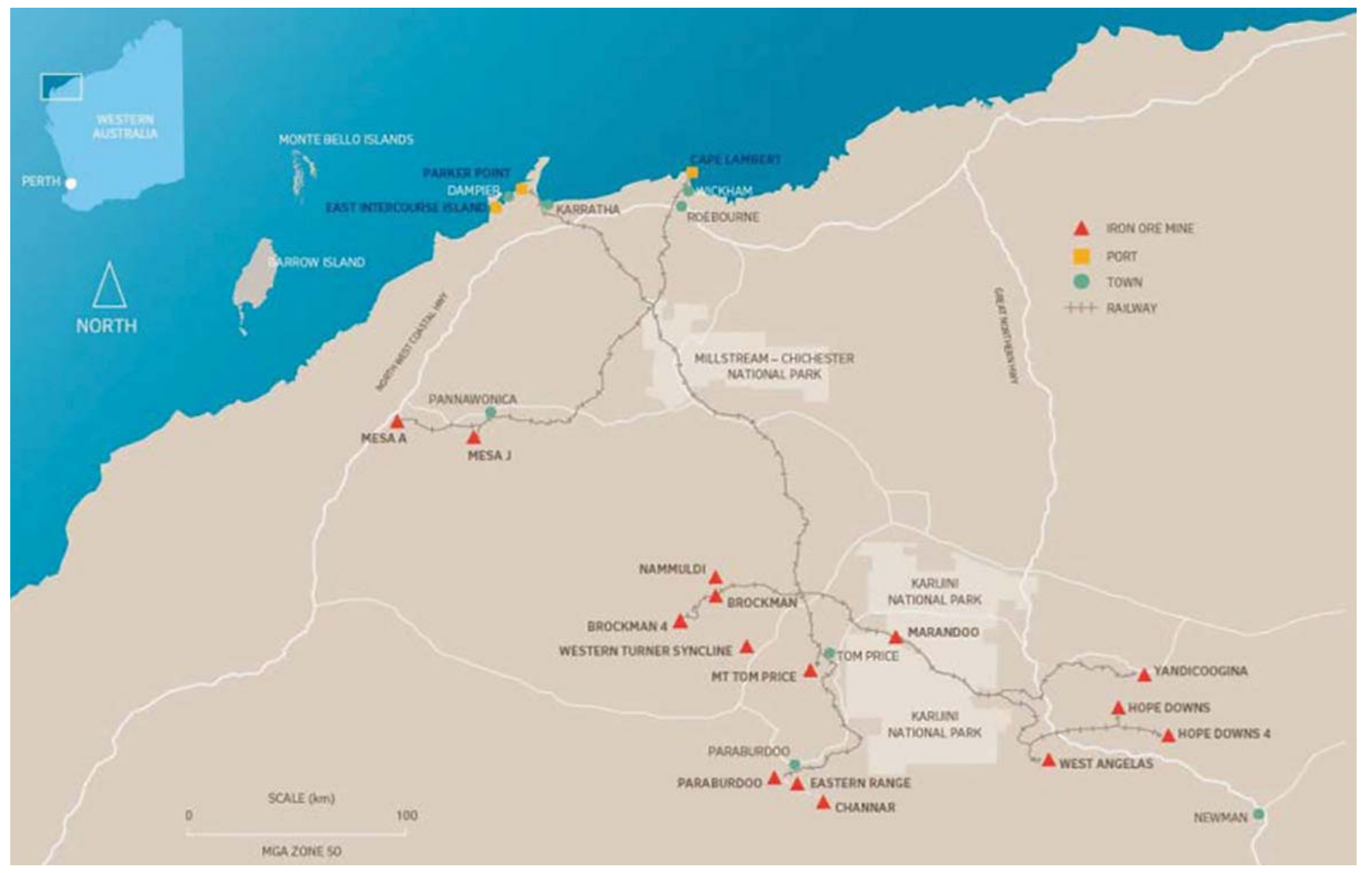

Figure 1-Rio Tinto Iron Ore operations in the Pilbara, Western Australia

A Technical Services Geotechnical Assurance group was established to provide across-site support, with responsibility for the development and commissioning of standardized tools and systems to manage geotechnical risk across the Pilbara Operations. The focus of this team is to protect the mine plan and ensure 'zero harm' safety outcomes during production ramp-up.

In early 2010, two events prompted a review of the RTIO geotechnical management systems:

(1) The introduction of a new Rio Tinto corporate standard: 'D3 Management of pit slopes, stockpiles, spoil and waste dumps'

(2) A significant slope instability at the West Angelas mine (described by Joass et al., 2013).

The outcome of the review highlighted the need for improved management of geotechnical risk, including clarity of design recommendations for implementation and effective reconciliation of key design assumptions with improved slope performance, slope monitoring alarm notification, and system health monitoring.

It was clear that a more structured approach was required to ensure transparent, auditable, and sustainable geotechnical risk management. In particular, a scalable system was needed to cope with the planned ramp-up and increased risk associated with (i) additional pits, (ii) wider geographical spread of operations, and (iii) increased vertical advance rates below the water table.

The approach to remediate the slope monitoring system shortcomings has been presented previously (de Graaf and Wessels, 2013).
This paper addresses the improved risk-based geotechnical management system (GMS) implemented across the RTIO Pilbara Operations.

\section{The need for slope management}

Effective slope management is an obvious prerequisite and enabler for safe and economic open pit operation - the scope of which can be significant. Statutory and corporate governance provide a framework with which operations must comply.

Regulations and corporate standards require that appropriate slope designs are developed and implemented. The legislative requirements principally focus on the safety requirements and penalties in the case of noncompliance and/or adverse findings. Although the key focus of the corporate standard is the management of slope-related risks, (which may exceed the local legislative requirements, depending on the jurisdiction), a well-managed slope provides the added advantage of satisfying shareholders' demands for maximizing profit through efficient mining.

\section{Legislative requirements}

RTIO's Pilbara mines are governed by the Western Australian Mines Safety and Inspection Act (1994) (MSIA) and the Mines Safety and Inspection Regulations (1995) (MSIR). Regulation 13.8 of those regulations pertains specifically to the application of sound geotechnical engineering practice in open pit mines.

Experience and professional judgement are important aspects of geotechnical engineering that are not easily 


\section{A framework for managing geotechnical risk across multiple operations}

quantified, but which can contribute significantly to the formulation of various acceptable and equally viable solutions to a particular mining problem. Management at each mining operation should recognize, identify, and address the geotechnical issues that are unique to each mine, using current geotechnical knowledge, methodology, and software and hardware appropriate to the situation. On this basis, the then WA Department of Minerals and Energy (DME) issued guidelines 'Geotechnical Considerations in Open Pit Mines' (1999), specifically to provide further explanation of the requirements of Regulation 13.8 and provide examples of good geotechnical engineering practice. The DME also encourages the application of current geotechnical knowledge, methodology, instrumentation, and 'ground support and reinforcement' techniques and hardware to the practical solution of geotechnical engineering issues in open pit mining.

\section{Corporate standards}

Rio Tinto Safety Standard 'D3: Management of pit slopes, stockpiles, spoil and waste dumps' (2010) provides a corporate standard for management of geotechnical hazards across all Rio-managed operations. The standard covers all geotechnical activities related to open pit mining, from design through implementation and verification. The application of the standard ensures that mines are designed, constructed, operated, and decommissioned on the basis of defensible, rigorous, and verifiable approaches to the management of business risks and achievement of Rio Tinto's business objectives. The standard requires that:

> Pit slope and dump design follow an engineering process that results in a geometry that meets safety and economic objectives, and is adopted in support of mine planning, mine development, and closure

> Implementation encompasses the application of the design, and geotechnical hazard management systems and processes that are put in place to support mine operations through to closure, and post-closure

> Verification involves applying monitoring and measurement processes and systems to reconcile the implemented design performance and conformance, with the design

> Design, implementation, and verification are part of a holistic process for the creation of slopes that promote both safety and economic mining goals.

To achieve these objectives, it is necessary to formalize the management of geotechnical and associated risks across business units and employ robust processes and systems for managing risks. The standard mandates the development and implementation of slope and dump management plans. These are equivalent to ground control management plans, which are recommended in the DME (1999) guidance note, or Code of Practice as required in other jurisdictions.

The overall objective for regulators is to ensure a safe working environment, and consequently the slope design must take into account the in situ conditions and planned mining strategy, and demonstrate that geotechnical risks are appropriately managed, whereas corporate standards combine the safety and economic requirements and maximize profit by ensuring designs are optimized.

\section{Risk-based approach}

The evaluation and management of risk is an ongoing function throughout the life of a mining project. Uncontrolled slope instability can have significant safety and economic impacts, and consequently typically features in the top ten risks for most open pit operations. Lack of certainty of design and mine plan inputs and assumptions presents a risk of adverse outcomes; but also may present upside potential or opportunity if more favourable outcomes are realized. Sharon (2009) describes risk management as the culture, process, and structure directed toward realizing potential opportunities while managing adverse effects. It is the authors' opinion that risk management requires end-to-end integration and needs to be maintained current with changing conditions and ongoing evaluation of effectiveness of controls.

To effectively use a risk management process it is important to understand the principles that underlie effective risk management. The international risk standard ISO 31000:2009 Risk Management - Principles and Guidelines includes a set of eleven principles for consideration. Hillson (2011) provides an excellent summary of and commentary on these principles: 'Each of which tells us something important about risk management, and together they set a challenging target for organisations who want to manage risk well. Some of them are obvious, but others may need a little explanation. Risk management should:

1) create and protect value. Risk management helps us to optimize our performance. It also protects value by minimizing the effect of downside risk, avoiding waste and rework.

2) be an integral part of all organizational processes. Risk management is not a stand-alone activity, and it should be 'built-in not bolt-on'. Everything we do should take account of risk.

3) be a part of decision-making. When we are faced with important situations that involve significant uncertainty, our decisions need to be risk-informed.

4) explicitly addresses uncertainty. All sources and forms of uncertainty need to be considered, not just 'risk events'. This includes ambiguity, variability, complexity, change etc.

5) be systematic, structured and timely. The risk process should be conducted in a disciplined way to maximise its effectiveness and efficiency.

6) be based on the best available information. We will never have perfect information, but we should always be sure to use every source, being aware of its limitations.

7) be tailorable. There is no 'one-size-fits-all' approach that suits everyone. We need to adjust the process to match the specific risk challenge that we face.

8) take human and cultural factors into account. Risk is managed by people, not processes or techniques. We need to recognize the existence of different risk perceptions and risk attitudes.

9) be transparent and inclusive. We must communicate honestly about risk to our stakeholders and decisionmakers, even if the message is unwelcome to some. 


\section{A framework for managing geotechnical risk across multiple operations}

10) be dynamic, iterative and responsive to change. Risk changes constantly, and the risk process needs to stay up to date, reviewing existing risks and identifying new ones.

11) facilitate continual improvement of the organisation. Our management of risk should improve with time as we learn lessons from the past in order to benefit the future.'

These principles make risk management more effective; they have been central to the practical development of the approach described in this paper, and are in alignment with corporate risk management requirements.

The geotechnical management plans of some large open pit operations rely almost exclusively on 'slope displacement' action plans based on experience rather than risk assessment. Good examples of geotechnical risk management and mitigation systems for large open pits are presented by Bye et al. (2005), Hearth (2007), and Ginting et al. (2011).

These approaches are appropriate where resources and personnel are focused on a single pit environment. However, due to the wide geographical spread of pits at individual mine operations and across the Pilbara, a risk-based approach was needed to prioritize and allocate resources. To give an indication of the substantial spatial challenges, the current Paraburdoo Mine produces $>20 \mathrm{Mt} / \mathrm{a}$ ore from 30 pits spread along $34 \mathrm{~km}$ of the Central and Eastern Range ridge line. A scalable yet flexible system was needed to evaluate and manage geotechnical risk. Furthermore, a standardized reporting approach to quantify, prioritize, and track implementation of controls, and which would also allow for reporting on risk type across the Pilbara operations, was required.

Hamman (2009) and Canbulat et al. (2013) present pit risk rating systems that can be used to evaluate the geotechnical risk 'status' of mines. This information can then be used to rate an individual mine within a company against others, or internally to determine whether geotechnical management has improved over time. These tools were developed to provide a high-level business-wide risk overview. The principal limitation of these systems is that the entire operation is evaluated in a single risk assessment. There is no provision for evaluating individual slope sectors and various modes of instability; consequently there is limited scope to use these tools to evaluate appropriate levels of control to be used for operational risk management.

Sharon (2009) suggests that operational risk management requires collaborative exchanges involving the development of risk assessments and evolution of improved and sustainable management practices; and that the principal goals of a geotechnical management programme are achieved with an effective performance monitoring system, developed jointly with the mine operators. The authors have extended this approach such that the justification and deployment of monitoring systems is risk-based. This provides a defensible justification for short- and long-term planning as well as budget planning.

\section{Design, implementation, and verification}

RTIO has developed a slope management framework in compliance with legislative and corporate governance requirements. This process aligns with the robust engineering design principles of ensuring that the design loop is closed through operational feedback, where input and outputs of each stage are aligned to enable effective engineering optimization. This can be displayed as a diagram representing a design-implementation-verification cycle (Figure 2). This is an iterative process that should be worked through a number of times as mining progresses to ensure that the slope design process is honed.

\section{The geotechnical management system}

The large number of operational pits across RTIO's 16 operations in the Pilbara requires a standardized and riskbased approach to managing geotechnical risks to ensure

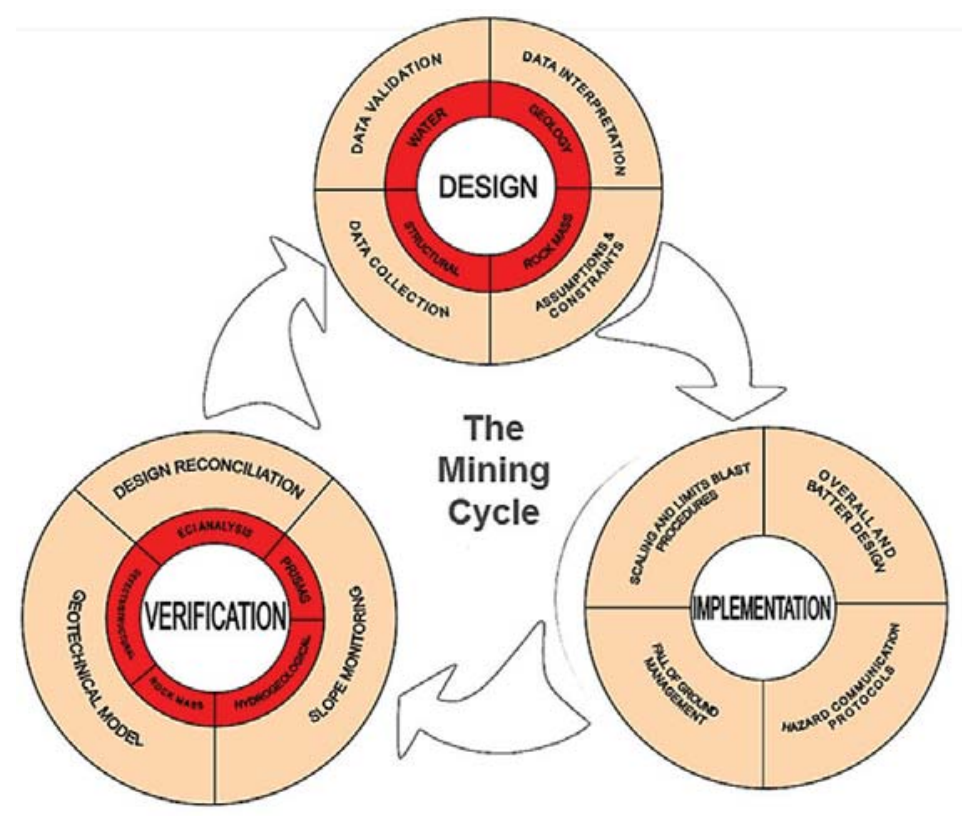

Figure 2-Design-implementation-verification work cycle (adapted from Hutchinson and Diederichs, 1996) 


\section{A framework for managing geotechnical risk across multiple operations}

resources and effort are focused in the right areas. A standardized approach facilitates the reporting, management, and auditing of geotechnical risks across the multiple operations to a centralized management.

RTIO developed a systematic framework to ensure that potential geotechnical risks are identified early and rigorously evaluated to allow effective controls to be identified and implemented. Figure 3 illustrates the geotechnical management system (GMS) developed by RTIO in alignment with the design-implementation-verification work cycle.

\section{Geotechnical design}

Geotechnical design is undertaken in line with the corporate study progression guidelines and is commensurate with the level of risk associated with the design and rock mass conditions. As most significant designs are undertaken by Perth-based engineers and consultants, a rigorous design engagement process with site-based engineers is implemented to ensure that key design assumptions, limitations, risks, and opportunities are understood by the site teams. All designs are based on the following mine design principles:

> Satisfy Western Australian MSIA and MSIR requirements

> Satisfy Rio Tinto corporate slope and waste dump safety standard

- Satisfy RTIO geotechnical design acceptance criteria

> Must be operationally achievable (comply with minimum mining width and equipment limitations)

> Design flexibility reflects the current data confidence, topographical constrains

> Most acceptable safe economic outcome (ore recovery $v s$ waste)

> Achievable to full depth based upon current orebody knowledge and life-of-mine directives
> Designs based on industry-accepted practice, geotechnical design methods, and independently peer reviewed as required

> Design risks must be acceptable to the business. Areas of geotechnical uncertainty and knowledge limits, along with any known/recommended actions and their timelines, must be communicated by the design team.

Departures from the design principles are justified by risk assessment and supported by an appropriate management plan.

\section{Implementation}

Geotechnical slope management systems that ensure safe operations at RTIO mine sites include technical procedures and systems (administered by the Technical Services group), and safe work procedures and systems mandated by Operations. One of the main technical systems is the geotechnical risk and hazard management system (GRAHAMS). This is a database of all the geotechnical risks on site and is the 'core' of the GMS. GRAHAMS includes functionality to assess and manage the current potential (asbuilt slope) and future potential (design slope) risks, leading to the development of monitoring plans and associated area management plans. Responses to conditions exceeding monitoring thresholds or other indications of slope instability are documented in geotechnical trigger action response plans (TARPS). Geotechnical hazards are communicated with hazard alert and maps, while the face risk assessment procedure and geotechnical awareness training provide nongeotechnical personnel with the knowledge to ensure a safe working environment.

\section{Verification}

Slope reconciliation is an essential component of the design process to confirm design parameters used in the feasibility studies. Verification of these parameters is a key step in

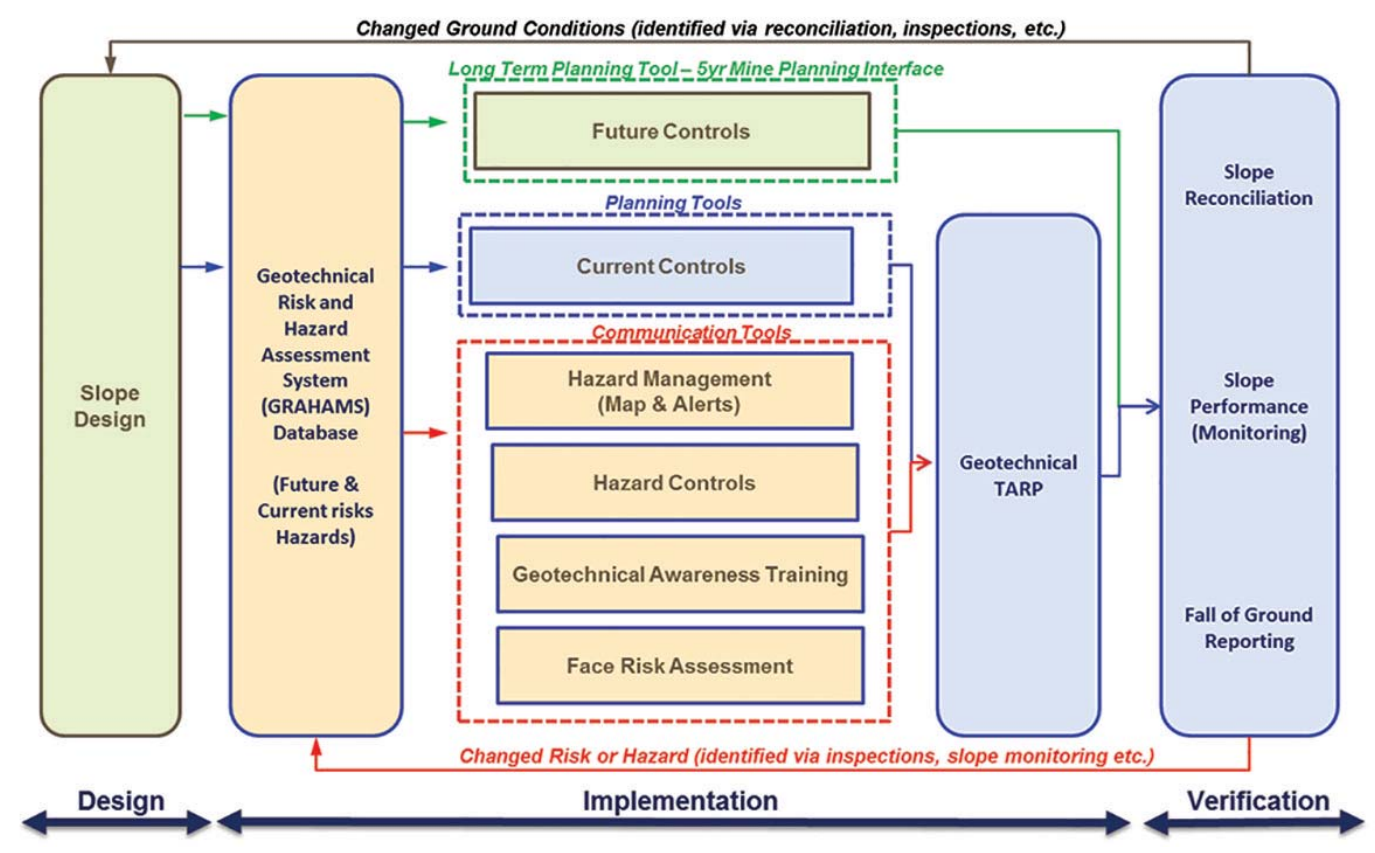




\section{A framework for managing geotechnical risk across multiple operations}

ensuring that the original design assumptions and recommendations are valid and that the design remains suitable for current conditions.

The geotechnical reconciliation process is the last step of the GMS and is designed to close the loop by providing feedback into the design process. This reconciliation process aims to compare all major input parameters utilized in slope design studies with current conditions. Any significant differences between observed and accepted design parameters are highlighted - these may present a risk or an opportunity. Negative reconciliation triggers design remediation studies, while positive reconciliation presents an opportunity to optimize the design.

\section{GMS requirements}

Systems engineering encourages the use of tools and methods to better comprehend and manage complexity in systems, but requires that the process is well documented and supported with appropriate training and routine checking (ensuring effective implementation) and periodic review to identify areas of improvement to fine-tune the system. The GMS is a management plan, backed by an organized system of supporting documents describing the design, implementation, and verification to maintain safe operations. This is to ensure that the system is sustainable. Figure 4 illustrates this framework.

Essential aspects of the RTIO GMS include:

1. Documentation-The primary document is the Slope and Dump Management Plan; this outlines the integration of all geotechnical risk management throughout the design, implementation, and verification process. Other key documents include the geotechnical trigger action response plan and various technical guidance notes covering key aspects of the work cycle and functional use of the tools and systems. These documents include:

(a) Appointments of mandatory accountable roles: registered manager, quarry manager, qualified (geotechnical) individual(s), and individuals authorized to make changes to designs (slope/dump/ blast etc.).

(b) RACI matrices identifying roles and accountabilities for all elements of the work flow

2. Systems and tools-includes:

(a) Mine design approval system, managing and tracking approval of the 'design of record' as well as a repository of supporting technical information pertaining to the design

(b) Geotechnical hazard and risk management (GRAHAMS)

(c) Face risk assessment system, ensuring operational risks are appropriately addressed when working on foot adjacent to slopes.

3. Training-Basic geotechnical hazard awareness training for all personnel, and advanced training for supervisors and personnel working in higher risk areas

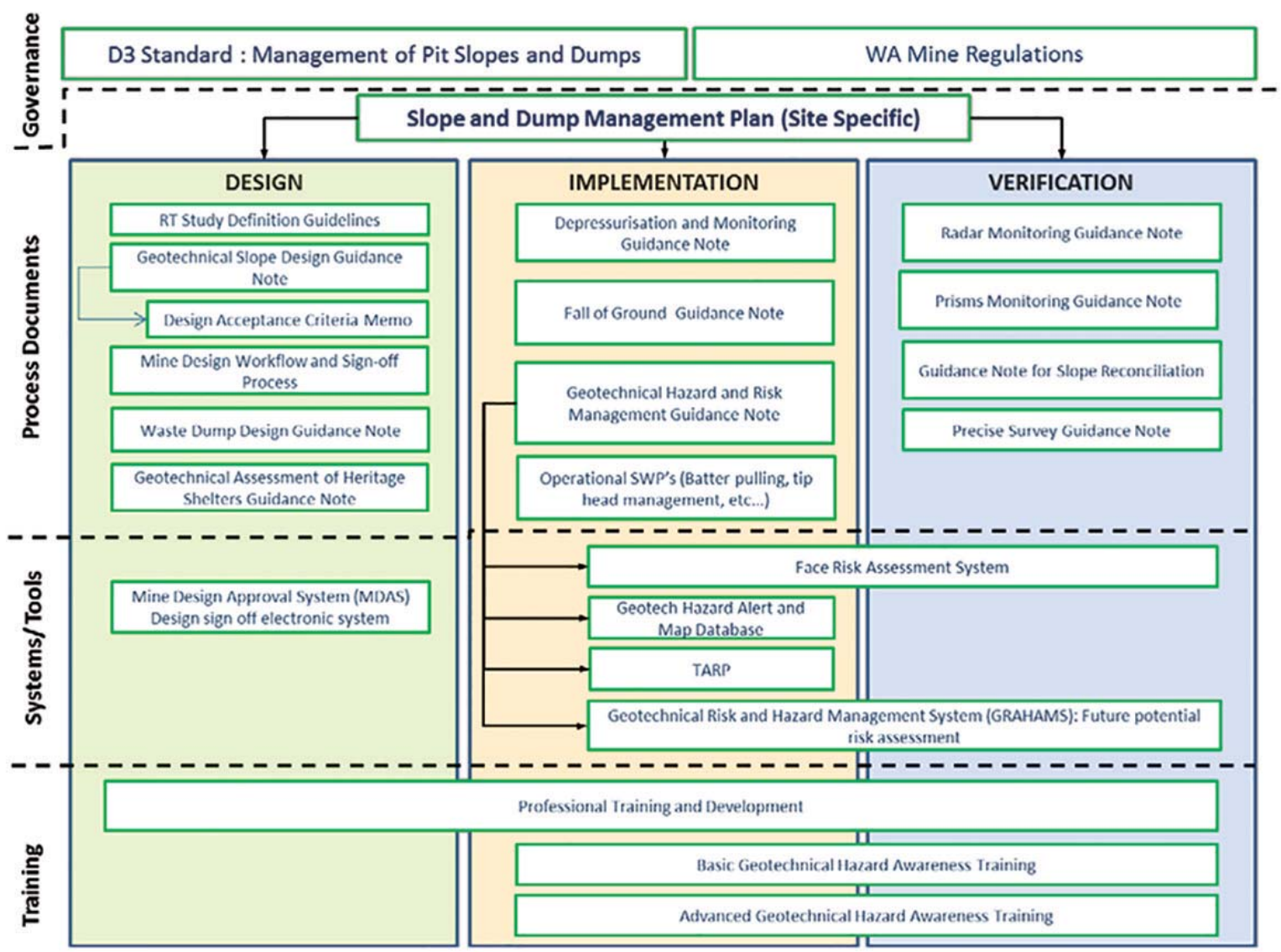

Figure 4-Summary of governance requirements and RTIO GMS supporting framework of documentation, systems, and training 


\section{A framework for managing geotechnical risk across multiple operations}

4. Regular audits and reviews-Routine reviews and internal checks are undertaken by the assurance team. Rio Tinto HSE undertakes (external) system and compliance audits (similar to other HSE Stand requirements). External technical reviews are undertaken annually.

It is imperative that the GMS is 'live' and owned and operated by the site teams - significant effort is expended in rolling out and implementing the system to ensure that all parties understand their accountabilities and roles in maintaining the system.

\section{GRAHAMS}

The GRAHAMS (see Figure 3) is a tool that was developed by RTIO to capture all the geotechnical risk assessments, consisting of a SOL database with an MS Access front end.

Risk assessments are conducted for predetermined risk assessment slope sectors (RASSs). These generally align with the slope design sectors. Failure mechanisms, geological structures, geology, and slope orientation can all play a role in the determination of the RASS boundaries. Risk assessments are done for three scale scenarios for each RASS, i.e. multi-batter, batter scale, and rockfalls. Dump risks are also assessed.

The risk assessment methodology is compliant with the Rio Tinto $5 \times 5$ qualitative risk assessment matrix; considering the consequence and likelihood of a scenario to derive the risk level. As a minimum, the safety and economic risk are assessed, but the system also allows for other impacts to be evaluated, e.g. reputational, environmental, community etc.

The data capture form of the GRAHAMS is shown in Figure 5. The first section of the inputs relates to the information regarding the hazard, including a description, details of the scale (multi-batter, batter, or rockfall), the likelihood of the hazard eventuating, and the controls in place to prevent the hazard. In the second part (which is the main section to be populated) particulars of the specific scenario are recorded. These include a description, the current controls, and assessment of the risk (likelihood and consequences). If applicable, the future controls are listed, as well as the predicted risk.

Two periods are considered for the risk assessments current and future potential. The difference and the need for current and future potential assessments are illustrated in Figure 5.

Current potential risk assessments assess the risk related to current slope geometry, projected to include planned mining for the next 6 months, and future potential assessments evaluate the complete height of the final (yet to be excavated) slope. This approach ensures that controls are commensurate with the level of risk posed to current operations, while planning and preparations can be done for future controls.

Critical controls are those controls that, should they be lost or become inactive, the risk level will immediately change to high or critical. Examples of critical controls are slope radar, automated prism monitoring, or a physical barrier. Critical controls are identified and tagged during the assessment process. This tagging allows the critical controls to be summarized in a separate report. Operations and line management should be aware of the critical controls. When a critical control is compromised the geotechnical team should be informed and evacuation of the area should be considered.

Reporting of risk levels can be carried at different levels (refer to Figure 6): per slope sector in a pit, per pit in a mining area, per mining area in a mining operation, or per operation across all the sites. In Figure 6 the top graphic shows the risk profile across all operations, while the pie charts shows the detail of a specific mine operation. This flexibility provides management with the opportunity to identify areas with elevated risk and allocate resources accordingly. For mine managers it provides a dashboard summary that indicates the risk profile across the different mining areas; and for general managers it provides an overview across the Pilbara operations.

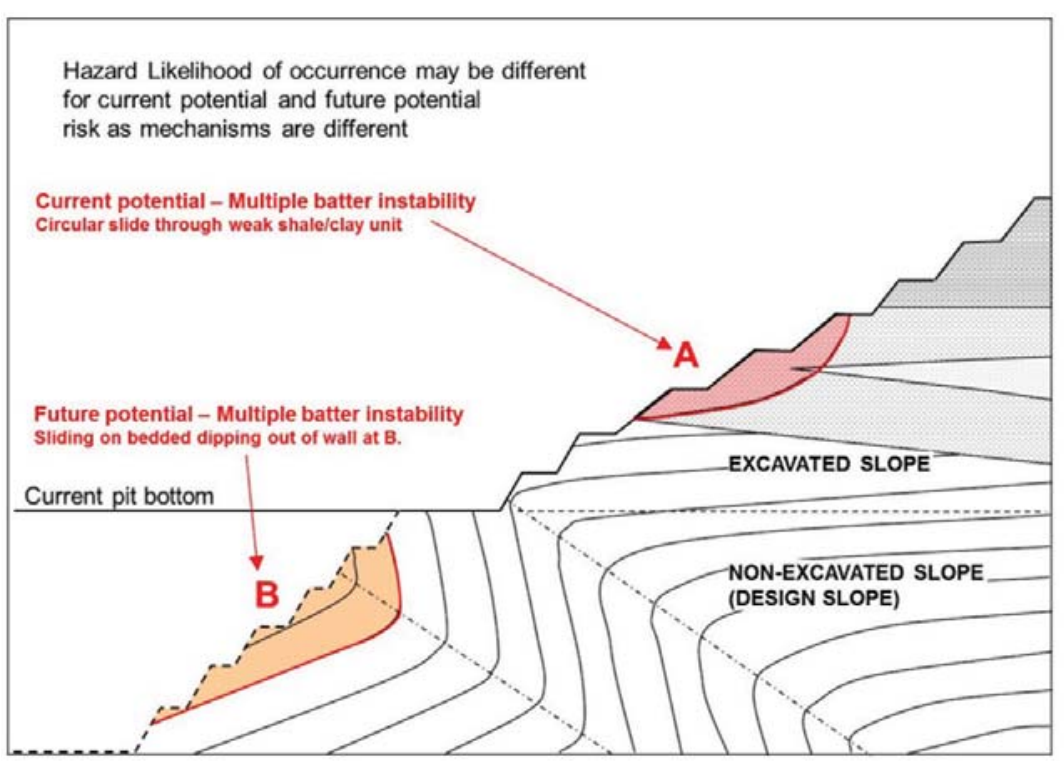

Figure 5-Schematic illustrating geometrical relationships between current and future potential assessments 


\section{A framework for managing geotechnical risk across multiple operations}

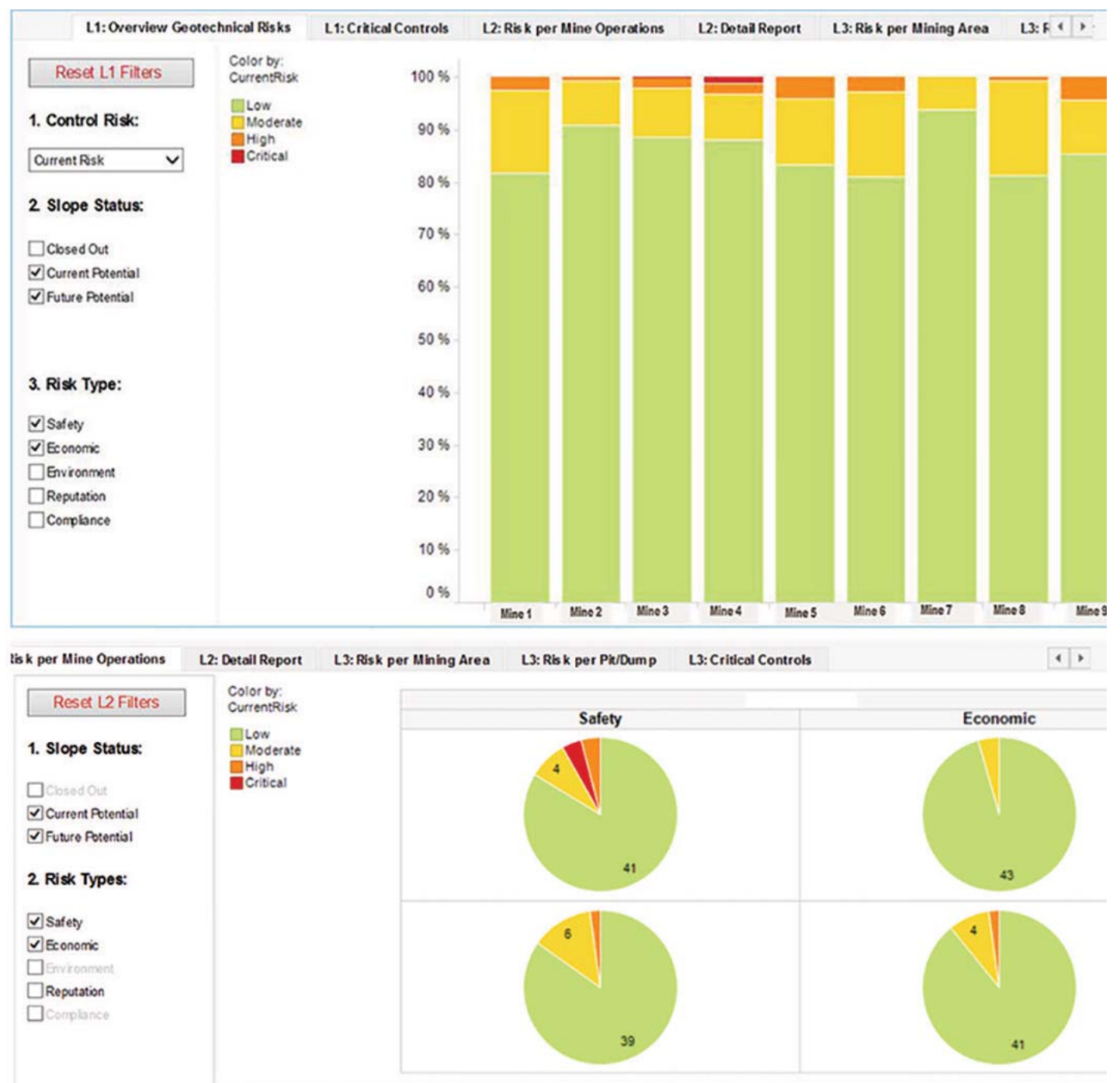

Figure 6-Example GRAHAMS report output. These example charts are for illustrative purposes only and are not representative of the actual RTIO risk profiles

Risk assessments are carried out by defining the geotechnical hazard and assessing both consequences and probability of occurrence. The current risk is assessed, i.e. the existing controls are taken into account, and when the assessed current risk level is considered unacceptably high, the predicted risk is assessed with the inclusion of future controls.

\section{Slope monitoring plan}

As an outcome of the GRAHAMS, all mining areas are riskassessed and ranked. This provides the basis for decisions regarding the level of resources and management required for each mining area. Best practice for slope performance monitoring is through a multi-layered approach whereby additional controls are implemented depending on the slope risk level. Basic monitoring for low-risk slopes may include infrequent berm inspections, whereas radar may be used for critical risk slopes where near-real-time monitoring is warranted. As the slope risk increases, improved data accuracy and frequency of readings are required, e.g. manually read crack pins are much less accurate than prism readings, while slope radar can provide 'sub-millimetre' accuracy. Table I details the RTIO risk-based hierarchical approach to slope monitoring systems.

RTIO uses the GRAHAMS output to implement this risk approach. Current and future controls needed to mitigate elevated risk profiles are identified during the risk assessment process. Accountabilities and frequency of current controls (where applicable) are summarized in the 'geotechnical monitoring plan' - an output from the GRAHAMS. Controls with recurring frequencies, e.g. monthly inspections and weekly monitoring, can be tabulated with the target frequency and dates as an output from GRAHAMS. Confirmation that a control was implemented, e.g. an inspection conducted, can be recorded in the system. A change in the monitoring schedule will automatically determine future implementation dates. This is an important planning tool for the site geotechnical team and also serves as auditable evidence that controls were in place. The 'future controls' requirements are included in the budgeting process to ensure availability when required. A summary of critical controls and accountabilities provides the opportunity to 


\section{A framework for managing geotechnical risk across multiple operations}

Table I

RTIO risk-based approach to slope monitoring

\begin{tabular}{|c|c|c|c|}
\hline Slope risk & Monitoring method & Monitoring frequency & Access required \\
\hline \multirow[t]{2}{*}{ Low risk } & Berm inspections (crack inspections) & \multirow{7}{*}{$\begin{array}{c}\text { Increasing monitoring frequency (some can } \\
\text { be alarmed if approxiate telemetry and } \\
\text { alert systems are in place) }\end{array}$} & Access to berms \\
\hline & $\begin{array}{l}\text { Manually read crack monitors or surface } \\
\text { extensometers }\end{array}$ & & Access to berms \\
\hline \multirow{5}{*}{ Moderate risk } & Laser scanners & & Access to berms (install/maintenance) \\
\hline & Inclinometers & & Access to berms (readings) \\
\hline & TDR/VWP & & Access to berms (readings)/telemetry \\
\hline & Automated surface extensometers & & Access to berms (readings)/telemetry \\
\hline & Manually read prisms & & Initial access to berms (install/targets) \\
\hline High risk & ATS Prisms (Automated Total Station) & \multirow[t]{3}{*}{$\begin{array}{l}\text { Required near real time telemetry and } \\
\text { alarms (i.e. alert, alarm, evacuation) }\end{array}$} & Access to berms (install/maintenance) \\
\hline \multirow{2}{*}{$\begin{array}{l}\text { Critical risk } \\
\text { (Safety, crtical, } \\
\text { monitoring) }\end{array}$} & Radar & & Remote \\
\hline & $\begin{array}{c}\text { Automated surface extensometers with local } \\
\text { or remote alarms }\end{array}$ & & Remote \\
\hline
\end{tabular}

closely monitor these controls to ensure they are in place. This provides a robust, reliable, auditable, risk-based system for early detection of slope instability.

\section{Hazard management}

Communication of geotechnical hazards to operational personnel forms an important part of the management of geotechnical hazards. Personnel working in the pit and near slopes need to be aware of geotechnical hazards in or near their working area.

When a geotechnical hazard is identified on a RTIO operation, the details are documented in a hazard alert, including a description of the hazard, the controls that are in place (if any), needs for further controls, and the level of the risk posed by the hazard. Controls are discussed and approved by the quarry manager, who is accountable for the safe working environment on a Western Australian mine site. Hazard maps are mandatory documents for all RTIO Pilbara mine operations to communicate geotechnical hazards and are displayed in crib rooms, information centres, and other locations around the site, allowing all pit personnel access to the information.

It is expected that personnel and supervisors working in the pit will consult the hazard map to familiarize themselves with the geotechnical hazards in their working area before each shift.

The hazard alerts (and the hazard database) are part of GRAHAMS. There is a direct link between the risk assessments conducted for each RASS and the hazard alert. When a new hazard alert is generated in GRAHAMS, the user is prompted to review the risk assessment for that RASS and for the scale applicable in the hazard alert. This will ensure that the learnings from the hazard are incorporated into the risk assessment and that GRAHAMS is a live database that is updated with current slope performance.

\section{Working near slopes}

A face risk assessment (FRA) must be completed before work on foot less than $10 \mathrm{~m}$ from the slope can start. The process starts with consultation of the geotechnical hazard map. If a geotechnical hazard exists for the work area, the hazard level and associated hazard number should be noted in order to confirm that all required controls are in place. The level of risk indicated by the hazard map combined with the outcome of the FRA will determine the level of controls required before work can start.

A FRA is an onsite assessment of the face directly above the area where the work is taking place. The results determine the job hazard analysis (JHA) risk assessment, sign-off level requirements, and actions that must be completed prior to work commencing. Sign-off of the JHA indicates that effective controls have been identified. The FRA is valid for only one shift as conditions may change between shifts and will require reassessment. If conditions are observed to change during the shift a new FRA should be completed.

\section{Training}

Effective management of geotechnical risks requires that the workforce is trained and aware of geotechnical hazards. RTIO developed two levels of geotechnical awareness training to ensure we have 'Trained Eyes Everywhere' and to support the geotechnical teams.

Basic geotechnical hazard awareness training is provided to all mine operations personnel. This training provides the basics of geotechnical awareness in the open pit mining environment. The main focus of the training provides knowledge on (i) how to identify signs of instability, (ii) how to and to whom to report hazards, and (iii) where to find the information regarding the site's geotechnical hazards.

The advanced geotechnical awareness training targets supervisors and personnel that will work on foot within $10 \mathrm{~m}$ of batter faces or highwalls. The training provides more detail on types of monitoring and effectiveness of controls that can be implemented to mitigate geotechnical hazards. It also focuses on the FRA system and provides information on how each of the parameters listed in the FRA should be assessed. This empowers non-geotechnical personnel with the knowledge to effective conduct face risk assessments. 


\section{A framework for managing geotechnical risk across multiple operations}

Both the training sessions are competency-tested. The qualifications are managed through the RTIO mandatory competencies system and refresher training is required every two years. The training packages were initially classroombased but have since been developed into web-based interactive audiovisual training packages to ensure standardized delivery of training content and streamlined course administration.

\section{Slope reconciliation}

Dixon et al. (2011), describe RTIO's approach to prioritizing and determining the level of rigour required for slope reconciliation - a key control in the verification of the design. This is a subset of the geotechnical management system described in this paper.

Geotechnical slope reconciliation is an integral part of the GMS, as illustrated in Figure 3. The process is a feedback loop from field implementation, including field assessment and audit of the results back to the design. Geotechnical reconciliation addresses the following risks:

> Unexpected instability due to inappropriate design (design uncertainty not considered)

> Unexpected instability due to lack of regular monitoring of all areas of the pit slope (design uncertainty not managed appropriately)

> Sub-optimal slope design, where the design may be overly conservative (design uncertainty results in conservatism).

The geotechnical reconciliation process evaluates all major input parameters utilized in slope design studies. Any significant differences between observed and accepted design parameters shall be highlighted and if significant,

reassessment of the design shall be undertaken.

Reconciliation provides a formalized process for continually re-assessing the geotechnical risk of the entire pit area to avoid 'surprises' and allow early identification of risk to operational processes. The process also results in increased confidence when estimating geotechnical risk as data uncertainty is reduced. The aim is to provide sufficient early warning of changed conditions to enable options to be assessed for:

> Remediation by design to prevent development of instability in the first place. The end result is improved safety and productivity

> Design optimization to improve ore recovery or reduce waste stripping

> Modification and /or improvement to design implementation practices.

\section{Assurance}

To demonstrate ongoing performance of the GMS, and ensure compliance with legislative and corporate standards as well as internal operating requirements, regular audits and reviews are undertaken. These comprise both internal and external reviews:

$>$ Internal reviews:

- Technical Services geotechnical assurance team Monthly to quarterly site visits are conducted to confirm effective implementation of systems.
Technical support is provided to the operations teams by means of operational risk management and design advice. This regular engagement also provides an opportunity to identify areas for system improvement. Bi-annual GRAHAMS moderation reviews are undertaken to ensure consistency in approach and identify any critical risks that would benefit from Independent Technical Review Team (ITRT) review.

> External reviews:

- Rio Tinto HSE audits - System and compliance audits (similar to other HSE Standard requirements) every second year. Slope and dump management plans and operation compliance to the D3 standard requirements are assessed either by corporate Technology and Innovation (T\&I) or other business unit geotechnical engineers

- External (independent) technical reviews are undertaken in alternate years to the HSE audits. These reviews focus on the effectiveness of the implementation of the SDMP and supporting systems, as well as the designs. To date a pool of six external reviewers, familiar with the D3 and WA regulations, are rotated to provide these reviews

- DMP Mines Inspector visits - At least annual site visits are undertaken by the Special Geotechnical Inspector to confirm conformance to the Act and regulations. Periodic 'geotechnical considerations' audits covering the standards associated with the safe development, operation, and closure of open pit operations from a geotechnical perspective are also undertaken.

Peer review is a fundamental risk management process that must be in place. Peer reviews are hierarchical, as the level of expertise required to undertake a technical review must be commensurate with the level of risk and complexity associated with the project (Table II). A key aspect of this is 'independent' review, where an individual not directly involved in the development (or outcomes) of the design is engaged as a 'fresh set of eyes' to critically review the work. Critical-risk projects and operations require ITRT review; that is, a team of external subject matter experts to provide advice and guidance on technical issues.

\section{Conclusions}

Effective management of the geotechnical risks across the 100 operational and 160 additional planned pits within the RTIO Pilbara Operations portfolio has required a risk-based approach to systematically identify potential hazards, evaluate the business risk (safety, economic, environmental, reputational, etc.), and define appropriate slope management controls. The risk-based framework is in alignment with the business risk management strategy, and provides the basis for defining the level of rigour required for slope management, as well as for prioritizing deployment of resources.

This facilitates better understanding of design and orebody knowledge risks and opportunities, leading to 


\section{A framework for managing geotechnical risk across multiple operations}

\begin{tabular}{|c|c|c|c|}
\hline \multicolumn{4}{|c|}{ RTIO risk-based geotechnical review framework } \\
\hline \multirow{2}{*}{$\begin{array}{l}\text { Geotechnical risk } \\
\text { (GRAHAMS) }\end{array}$} & \multicolumn{3}{|c|}{ RTIO geotechnical reviews } \\
\hline & \multicolumn{2}{|r|}{ Mine operations } & Design \\
\hline Critical & \multirow[t]{4}{*}{$\begin{array}{l}\text { 2-yearly external (independent) } \\
\text { reviews (incl. operational designs). }\end{array}$} & \multirow[t]{4}{*}{$\begin{array}{l}\text { SDMPs reviewed and signed off by geotechnical } \\
\text { 'Qualified Individuals' and nominated D3 managers. }\end{array}$} & $\begin{array}{l}\text { Independent Technical Review Team } \\
\text { (ITRT) - typically external }\end{array}$ \\
\hline High & & & Independent technical peer review \\
\hline Moderate & & & Technical peer review \\
\hline Low & & & Technical peer review \\
\hline
\end{tabular}

improved hazard management across operations and focused attention on areas of elevated risk. Reporting on the geotechnical risk status on an individual pit basis, or grouped by mine operation or Pilbara-wide, is an important tool in managing geotechnical risks across multiple operations, where the mine output is blended to achieve the required marketable product specifications. Interruptions in supply (through slope instability) can significantly impact the blended product quality.

The geotechnical management system (GMS) has been successfully implemented across RTIO mine operations and is fundamental to effective geotechnical slope management in a multi-pit - multi-operations environment. Additionally, the system provides an auditable process with demonstrated compliance with WA mines regulations and Rio Tinto's corporate health and safety standard D3 'Management of pit slopes, stockpiles, spoil and waste dumps'.

\section{Acknowledgements and disclaimer}

The contributions of colleges in developing, maintaining and improving the GMS are acknowledged. In particular Julian Venter's contributions in the initial system inception, and Tim Johnson's role in the system documentation and rollout is recognized. The shared vision of the members of the assurance and operations teams over the years has contributed to the deployment of sustainable risk management system. Furthermore, permission from Rio Tinto management, to publish this work is also gratefully acknowledged.

All opinions and conclusions drawn in this paper are those of the authors alone and it should not be assumed that any views expressed herein are also necessarily those of RTIO and/or the individual mine owners.

\section{References}

Bye, A., LitTle, M., and Mossop, D. 2005. Slope stability risk management at Anglo Platinum's Sandsloot open pit. Proceedings of the Institute of Quarrying and ASPASA 36th Annual Conference and Exhibition, Birchwood, Gauteng, South Africa, 3-5 March 2005.

Canbulat, I., Hoelle, J., and Emery, J. 2013. Risk management in open cut coal mines. International Journal of Mining Science and Technology, vol. 23 , no. 3, May 2013. pp. 369-374.

De GrAAF, P.J.H. and WeSSELS, S.D.N. 2013. Slope monitoring and data visualisation state-of-the-art - advancing to Rio Tinto Iron Ore's Mine of the
Future $^{\mathrm{TM}}$. Proceedings of the International Symposium on Slope Stability in Open Pit Mining and Civil Engineering (Slope Stability 2013), Brisbane, Australia, 25-27 September 2013. Dight, P.M. (ed.). Australian Centre for Geomechanics, Perth. pp. 803-814.

Department of Minerals and Energy Western Australia. 1999. Guideline Geotechnical Considerations in Open Pit Mines. Government Printer, Perth.

Dixon, R.A., Johnson, T.M., DE GraAf, P.J.H., Wessels, S.D.N., and Venter, J. 2011. Risk based geotechnical slope reconciliation at Rio Tinto Iron Ore, Pilbara Operations. Proceedings of Slope Stability 2011: the International Symposium on Rock Slope Stability in Open Pit Mining and Civil Engineering, Vancouver, Canada, 18-21 September 2011. CIM, Montreal.

Ginting, A., StAwski, M., and Widiadi, R. 2011. Geotechnical risk management and mitigation at Grasberg open pit, PT Freeport Indonesia. Proceedings of Slope Stability 2011: the International Symposium on Slope Stability in Open Pit Mining and Civil Engineering, Vancouver, Canada, 12-21 September 2011. CIM, Montreal.

Herath, A. 2007. Pit slope management strategy at Mt Keith nickel operation, Western Australia, Proceedings of the International Symposium on Soil and Rock Engineering, Colombo, Sri Lanka, 6-11 August 2007. Sri Lankan Geotechnical Society

Hamman, E. 2009. Qualitative geotechnical hazard and risk assessment. Slope Stability 2009: Proceedings of the International Symposium on Slope Stability in Open Pit Mining and Civil Engineering, Santiago, Chile, 9-11 November 2009

Hillson, D. 2011. Risk Management Principles Part 1: ISO31000:2009. Risk Doctor Briefing, August 2011

Hutchinson, D. and Diederichs, M. 1996. Cable Bolting in Underground Mines. BiTech Publishers, Richmond, BC, Canada. 401 pp.

Joass, G., Dixon, R., Sikma, T., Wessels, S., Lapwood, J., and de GraAf, P. 2013. Risk management and remediation of the north wall slip, West Angelas mine, Western Australia. Slope Stability 2013: Proceedings of the International Symposium on Slope Stability in Open Pit Mining and Civil Engineering, Brisbane, Australia, 25-27 September 2013. Dight, P.M. (ed.). Australian Centre for Geomechanics, Perth.

SHARON, B. 2009. Risk management - geomechanics application for open pit slope design and performance. Slope Stability 2009: Proceedings of the International Symposium on Slope Stability in Open Pit Mining and Civil Engineering, Santiago, Chile, 9-11 November 2009.

Western Australia Government. 1994. Mines Safety and Inspection Act 1994. Government Printer, Perth.

Western Australia Government. 1995. Mines Safety and Inspection Regulations 1995. Government Printer, Perth. 